Bull. Chem. Soc. Ethiop. 2021, 35(3), 625-638.

(C) 2021 Chemical Society of Ethiopia and The Authors

ISSN 1011-3924

DOI: https://dx.doi.org/10.4314/bcse.v35i3.13

Printed in Ethiopia

Online ISSN 1726-801X

\title{
HIRSHFELD SURFACE ANALYSIS AND QUANTUM CHEMICAL STUDY OF MOLECULAR STRUCTURE OF PHOSPHATE
}

\author{
Abdellatif Rafik $^{1 *}$, Hafid Zouihri ${ }^{2}$ and Taoufiq Guedira ${ }^{1}$ \\ ${ }^{1}$ Laboratory of Organic Chemistry, Catalysis and Environment, Faculty of Sciences, Ibn Tofail \\ University, B.P. 133, 14000 Kenitra, Morocco \\ ${ }^{2}$ Laboratory of Chemistry of Materials and Biotechnology of Natural Products, University \\ Moulay Ismail, Faculty of Sciences, Meknes, Morocco
}

(Received June 19, 2019; Revised June 14, 2021; Accepted December 2, 2021)

\begin{abstract}
In this present study, Density fuctional theoretical computations are performed at (B3LYP, PBEPBE), HF and MP2 level with $3-21 G$ basis sets to derive optimized geometry and bonding features. The calculated geometrical parameters have been compared with experimental data. The intermolecular $\mathrm{O}-\mathrm{H}$...O and $\mathrm{N}-\mathrm{H}$... O hydrogen bonds are involved in crystal structure stabilization. An intramolecular $\mathrm{O}-\mathrm{H}$... N hydrogen bond is observed between the phosphate $\mathrm{OH}$ group and the $\mathrm{N}$ atom. Further, the molecular Hirshfeld surface analysis was carried out to reveal the nature of intermolecular contacts and the fingerprint plot provides the information about the percentage contribution and reveals that the O...H (44.1\%) interactions have the major contribution to form the crystal. The Mulliken population analysis and the HOMO-LUMO energy gaps show that the molecule has a good stability and from the calculation, we conclude that the molecule is really hard materials.
\end{abstract}

KEY WORDS: Energy gaps, Hydrogen bonds, Hirshfeld surface, Mulliken population, Phosphate

\section{INTRODUCTION}

In recent years, the chemistry of organic-inorganic hybrid materials have attracted much scientific and industrial attention due to their interesting properties and potential applications such as electric, magnetic, non-linear optical, catalytic properties [1]. Organic-inorganic hybrid compound provide a class of materials displaying interesting technological importance [2]. The ability to combine the properties of organic and inorganic compounds within one single compound leads to interesting crystal structures [3]. Hybrid organic-inorganic adducts are of current interest due to their intriguing architectures and potential applications in crystal engineering $[4,5]$. The intermolecular forces between the different components of these hybrid crystals are provided by hydrogen bonding or other non-covalent and non-ionic interactions [6]. Among these materials, organic phosphates are particularly interesting. It has been found that the hydrogen bonds and the nature of organic molecules seem to determine the molecular organization of these compounds as to build infinite anionic networks with various geometries: ribbons [7], chains [8], twodimensional networks [9], and three-dimensional networks [10]. In order to study the influence of hydrogen bonds in the molecular structure, the Hirshfeld surface analysis was used.

Hirshfeld surface based tools represent a novel approach to this problem $[11,12]$ the central element in this method is the derivation of the Hirshfeld surface an immediately interpretable visualization of a molecule within its environment and the decomposition of this surface to provide a molecular fingerprint a directly accessible $2 \mathrm{D}$ map that provides the full distribution of interactions. Analysis of intermolecular interactions using Hirshfeld surface-based tools represents a major advance in enabling supramolecular chemist to account insight into crystal packing behavior.

In the present work, the potential map of the complex molecule was obtained with the same

*Corresponding author. E-mail: abdellatif.rafik@uit.ac.ma

This work is licensed under the Creative Commons Attribution 4.0 International License 
base function and frontier molecular orbitals (FMOs) analysis including spin transitions have been explained in detail. Mulliken atomic charges and MEP were used to determine charge-dependent properties and interactions of molecules with each other. Further, to understand the intermolecular interactions of the crystal structure, Hirshfeld surface and fingerprint plots were performed.

\section{COMPUTATIONAL DETAILS}

The optimized molecular structure calculations of the title compound were performed using Gaussian 03 programme [13]. Density functional theory (DFT) with (B3LYP, PBEPBE), HF and MP2 levels with 3-21G basis sets was used for complete calculations [14-18]. HOMO and LUMO energies, Mullikens atomic charges were calculated. To estimate the chemical reactivity of the molecule, the molecular electrostatic potential (MEP) surface map of the compound was investigated with theoretical calculations at the B3LYP/3-21G level [19-21]. The molecular electrostatic potential (MEP) map, electrostatic potential contour map and frontier molecular orbitals (FMOs) were drawn using GAUSSIAN 03W package. The ORTEP and packing diagrams were generated using the software MERCURY [22].

\section{HIRSHFELD SURFACE}

Hirshfeld surfaces mapped over $\mathrm{d}_{\text {norm }}$ curvedness and 2D fingerprint plots were generated using Crystal Explorer 3.1 [23] and generating electrostatic potential [24] with TONTO [25], to analyze the close contacts in the title compound. The molecular Hirshfeld surfaces were generated using a standard (high) surface resolution with the $3 \mathrm{D} \mathrm{d}_{\text {norm }}$ surfaces mapped over a fixed color scale of -0.7706 to 1,172 . The curvedness was mapped in the color range of -4 to 0.4 , The electrostatic potential was mapped on Hirshfeld surfaces using Hartree Fock (STO-3 G basis set) theory over the range of -0.020 a.u. to +0.020 a.u. The electrostatic potential surfaces are plotted with red region which is a negative electrostatic potential (hydrogen acceptors) and blue region which is a positive electrostatic potential (hydrogen donor).

\section{Description of structure}

\section{RESULTS AND DISCUSSION}

The compound crystallizes in monoclinic P $2 / 1$ s space group [26]. A perspective view of the asymmetric unit of the structure drawing with $50 \%$ probability thermal ellipsoids is depicted in Figure 1, while the complete atomic arrangement is shown in Figure 2(a). The phosphate anion is stabilized by strong interactions with its environment; there are two types of $\mathrm{P}-\mathrm{O}$ bonds and three types of $\mathrm{O}-\mathrm{P}-\mathrm{O}$ angles. The bond lengths and angles of the phosphate anions are similar to those observed in 2-chloroanilinium dihydrogenmonophosphate [2CADHP], in accord with a tetrahedral configuration. This latter shows that the $\mathrm{H}_{2} \mathrm{PO}_{4}{ }^{-}$inorganic entities and $-\mathrm{NH}_{3}{ }^{+}$groups have a layered organization around the planes $\mathrm{z}=0$ and $\mathrm{z}=1 / 2$. Displaying In the organization of $\mathrm{H}_{2} \mathrm{PO}_{4}{ }^{-}$entities, it is noteworthy that the $\mathrm{O} \ldots \mathrm{O}$ distances involved in hydrogen bonds $(2.515(2)-$ $2.602(2) \mathrm{A}^{\circ}$ ), are of the same order of magnitude than the $\mathrm{O} \ldots \mathrm{O}$ distances in the $\mathrm{PO}_{4}$ tetrahedra (2.451(2)-2.527(2) show in in Fig. 2(a). In the two crystallographically independent $\mathrm{H}_{2} \mathrm{PO}_{4}^{-}$ anions, the $\mathrm{P}-\mathrm{O}$ bonds $(1.503(1)-1.570(2) \AA)$ are shorter than $\mathrm{P}-\mathrm{OH}$ bonds $(1.504(1)-1.553(1)$ $\AA)$. This is in agreement with the data relative to the protonated 2-chloroanilinium. The P-P distance $(4.705(4) \AA)$ is shorter than that observed in 2-chloroanilinium dihydrogen monophosphate.

Two crystallographically independent [2-chloroanilinium] groups exist also in this atomic arrangement. These organic groups are anchored onto successive inorganic layers through hydrogen bond involving the hydrogen atoms of the $\mathrm{NH}_{3}$ groups with $\mathrm{H}(\mathrm{N}) \ldots \mathrm{O}$ distances varying 
between 2.174(3) and 2.835(3) A. Interatomic distances and angles in these two independent groups exhibit usual values. The mean value of the $(\mathrm{C}-\mathrm{C})$ length of benzene cycle is 1.387(3) $\AA$, which is between single bond and double bonds and agrees with that in benzene. Furthermore, the distances of C (4)-C (5), C (5)-C (6) and N (1)-C (1) [1.375 (3), 1.387(3) and 1.454(3) A], clearly indicate three single bonds. (Figure $2(\mathrm{~b})$ ), show symmetry elements for color green has a corresponding symmetry operation $(1 / 2-x, 1 / 2+y, 1 / 2-z)$, identity 2 -fold screw axis with direction $[0,1,0]$, for color yellow has a corresponding symmetry operation $(-x,-y,-z)$, identity inversion centre, and color pink corresponding symmetry operation $(1 / 2+\mathrm{x}, 1 / 2-\mathrm{y}, 1 / 2+\mathrm{z})$, identity glide plane.

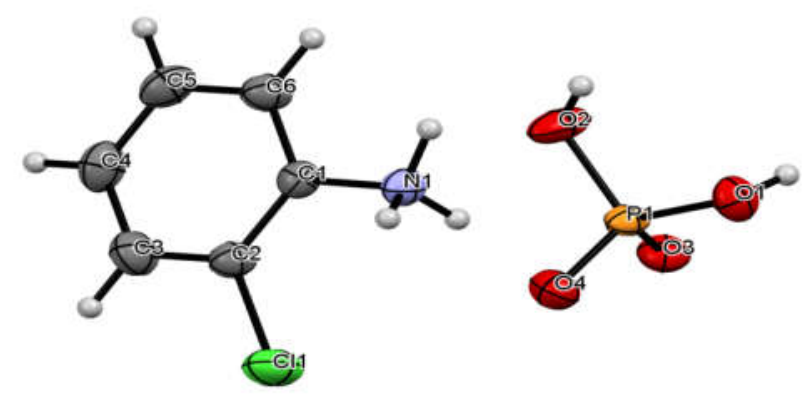

Figure 1. ORTEP of hybrid 2CADHP.

\section{HIRSHFELD SURFACE AND FINGER PRINT CALCULATION}

In addition, the Hirshfeld surface is mapped with $\mathrm{d}_{\text {norm }}$ (the normalized contact distance), which is normalized from de (the nearest external distance), di (the nearest internal distance) and the van der Waals (vdW) radii of the two atoms to the surface. The fingerprint plots are derived from the 3D Hirshfeld surface and provide a visual summary of the frequency of each combination of $\mathrm{d}_{\mathrm{e}}$ and $d_{i}$ across the surface of a molecule. Thus, they not only indicate which intermolecular interactions are present, but also provide information on the relative area of the surface corresponding to each kind of interaction [27].

The Hirshfeldd $d_{\text {norm }}$ surface, shape index and curvedness of the $\left(\mathrm{C}_{6} \mathrm{H}_{7} \mathrm{ClN}^{+}, \mathrm{H}_{2} \mathrm{PO}_{4}^{-}\right)$are shown in Figure 3, and the 2D fingerprint plots showing the percentage of area occupied by the different types of intermolecular interactions are depicted in Figure 4. The H...H and O...H intermolecular contacts appear as two distinct spikes of light sky-blue color and almost of same lengths respectively in the region $1.1 \AA<\left(\mathrm{d}_{\mathrm{e}}+\mathrm{d}_{\mathrm{i}}\right)<2.4 \AA$ and $1.0 \AA<\left(\mathrm{d}_{\mathrm{e}}+\mathrm{d}_{\mathrm{i}}\right)<2.45 \AA$ of the full fingerprint plots (Figure 4$)$. The red spots on the top and down of the $\mathrm{d}_{\text {norm }}$ surface are attributed to the $\mathrm{N}-\mathrm{H}$... O hydrogen bond which shows the closest intermolecular interactions in the compound. The small, flat segments delineated by the blue outline in the surface mapped with curvedness indicate the absence of $\pi \ldots \pi$ stacking interactions in the structure. In addition, these contacts are highlighted on the molecular surface using conventional mapping of $d_{n o r m}$, shape index ( -1 au to $1 \mathrm{au}$ ) and curvedness ( -4 a.u. to 0.4 a.u.). The dark red regions on the $d_{\text {norm }}$ surface are due to short inter contacts (strong hydrogen bonds), while the other interactions are appear as light-red spots. The red concave region on shape index is the surface around the acceptor atom and the blue region is the surface around the donor atoms. 


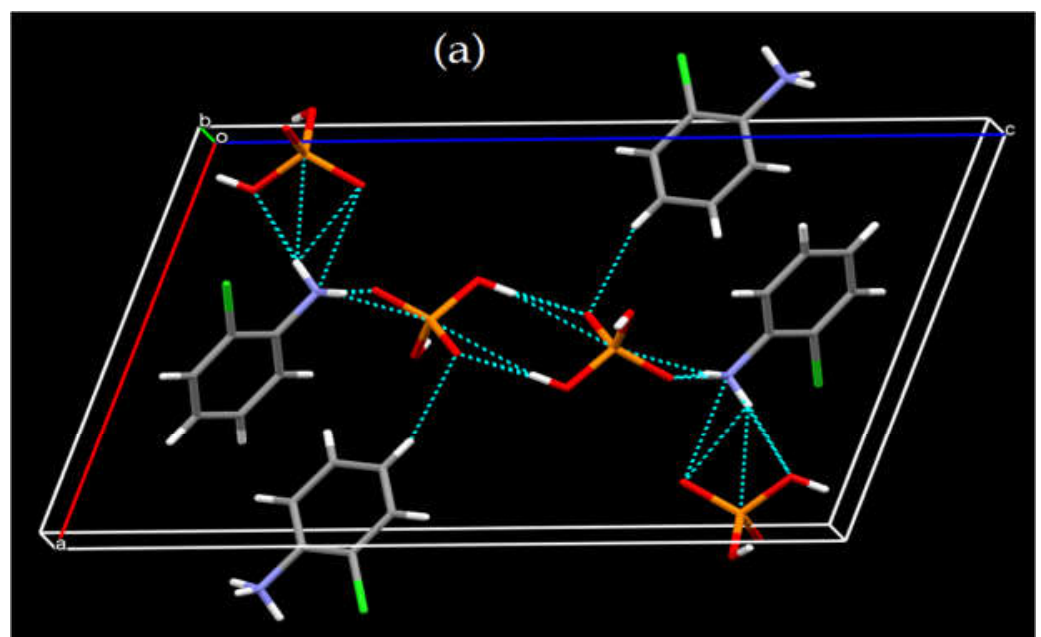

(b)

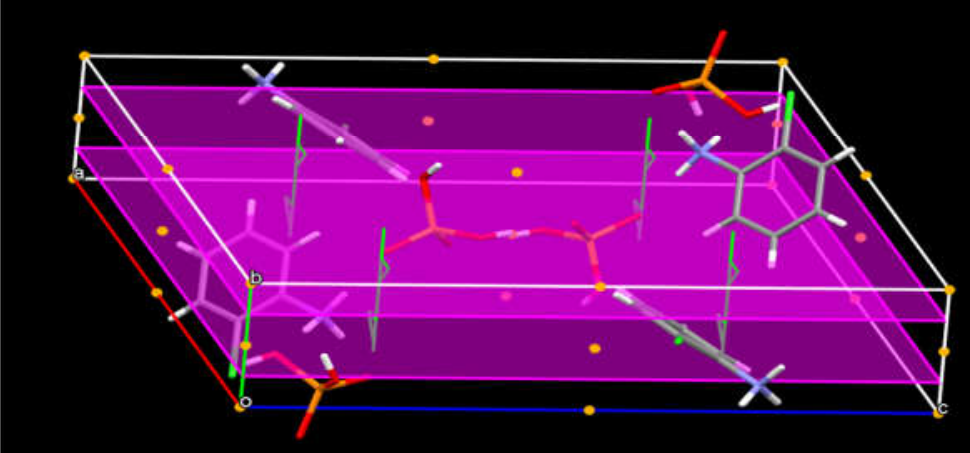

Figure 2. (a) Projection of the structure of 2CADHP along the b crystallographic axis, hydrogen bonds are shown as dashed lines and (b) showing all symmetry elements.

Furthermore, the 3D Hirshfeld surfaces have been mapped over $d_{\text {norm }}$, shape index, and curvedness as well as 2D fingerprint plots on the Hirshfeld surface analysis of the molecule shows that $\mathrm{O} \ldots \mathrm{H}$ and $\mathrm{H} \ldots \mathrm{H}$ interactions exhibit the most significant contributions (44.1 and $18.3 \%$ to the total Hirshfeld surfaces, respectively). The C...H intermolecular interactions appear as two very short spikes in the $2 \mathrm{D}$ fingerprint plots, contributing to $14.9 \%$. The $2 \mathrm{D}$ fingerprint plot reveals that the $\mathrm{Cl} \ldots \mathrm{H}$ interaction covers $13.2 \%$ of the total surface. Figure 5 contains the percentages of contributions for a variety of contacts in the title crystal structure. This quantitative conclusion shows that the $\mathrm{O} \ldots \mathrm{H}$ interactions represent the important percentage of total surface. The Hirshfeld surfaces certainly allow a detailed scrutiny by displaying all the intermolecular interactions within the crystal and this methodology has very important promise in crystal engineering. 
Hirshfeld surface analysis and quantum chemical study of molecular structure of phosphate 629

Interaction since there is no evidence of the adjacent red and blue triangles on the shape index surface. This result has been confirmed by X-ray crystal structural analysis. The surfaces are shown to allow visualization of the orientation and conformation of the functional groups in the molecules.

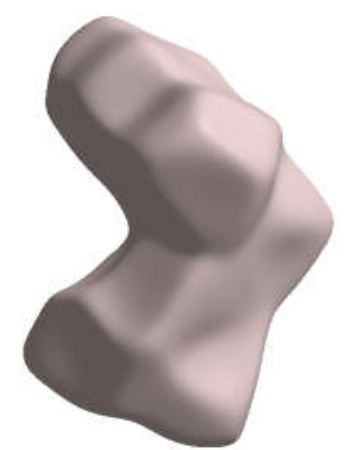

(a)

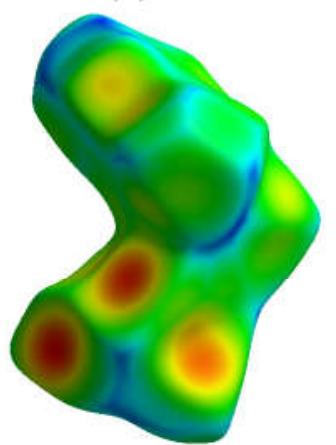

(c)

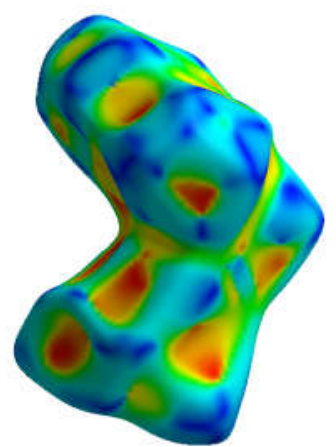

(e)

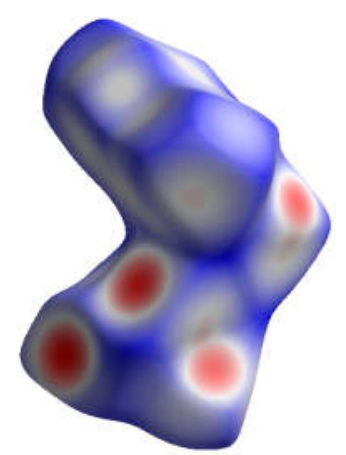

(b)

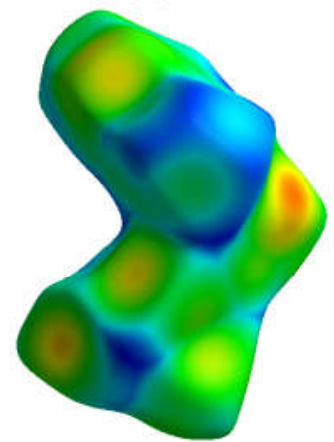

(d)

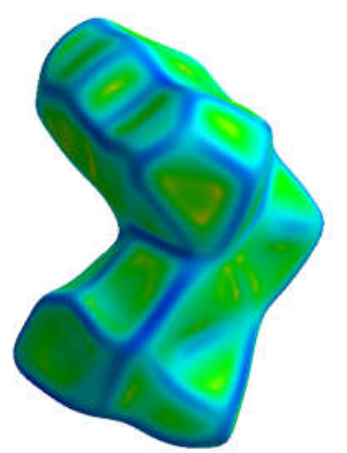

(f)

Figure 3. 3D Hirshfeld surfaces of 2CADHP (a) none, (b) $d_{\text {norm }} d_{i}$, (c) $d_{e}$, (d) (e) shape index and (f) curvedness. 


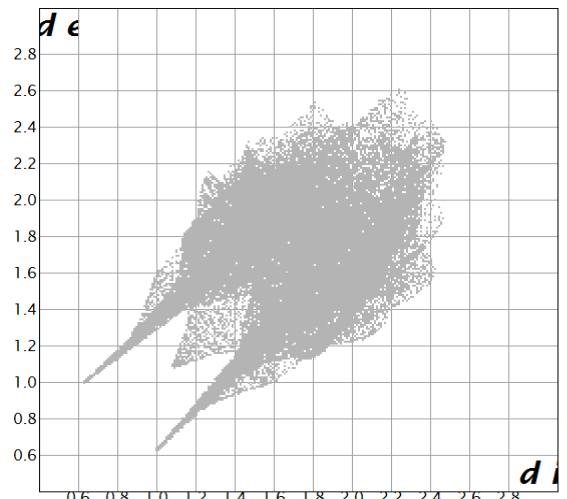

(a)

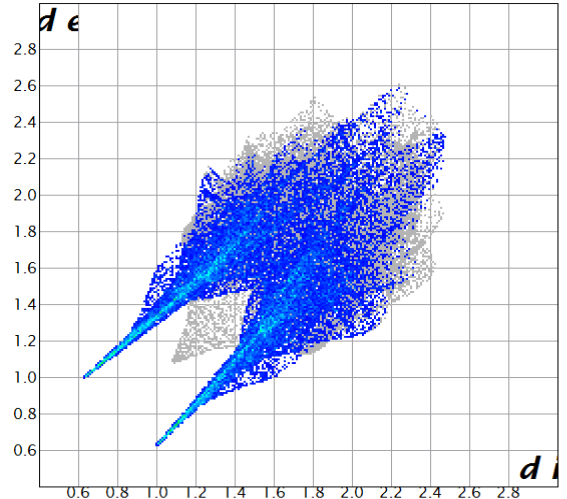

(c)

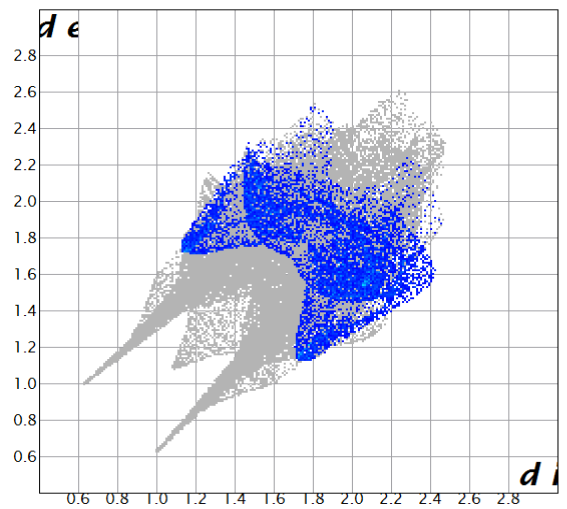

(e)

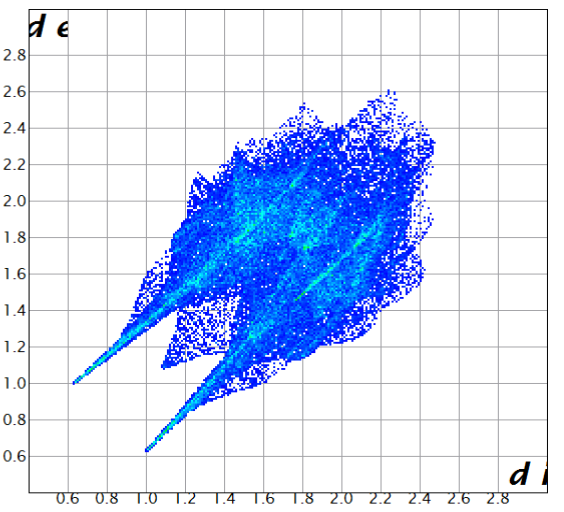

(b)

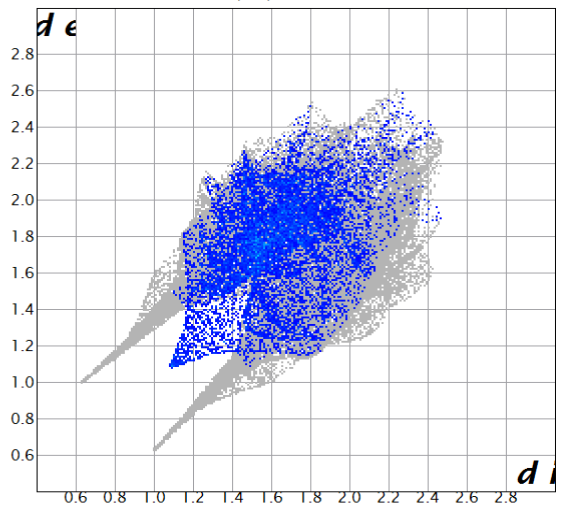

(d)

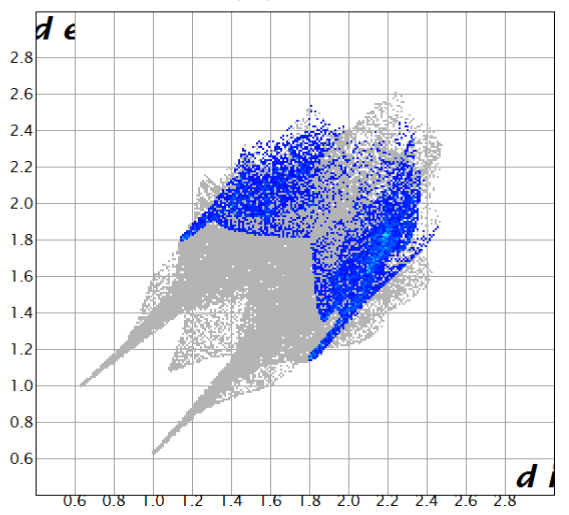

(f)

Figure 4. Fingerprint of the title compound, (a) Surface area included $(0,0 \%)$, (b) all...all, (c) $\mathrm{O} . . . \mathrm{H}$, (d) $\mathrm{H} . . . \mathrm{H}$, (e) C...H and (f) $\mathrm{Cl} \ldots \mathrm{H}$. 


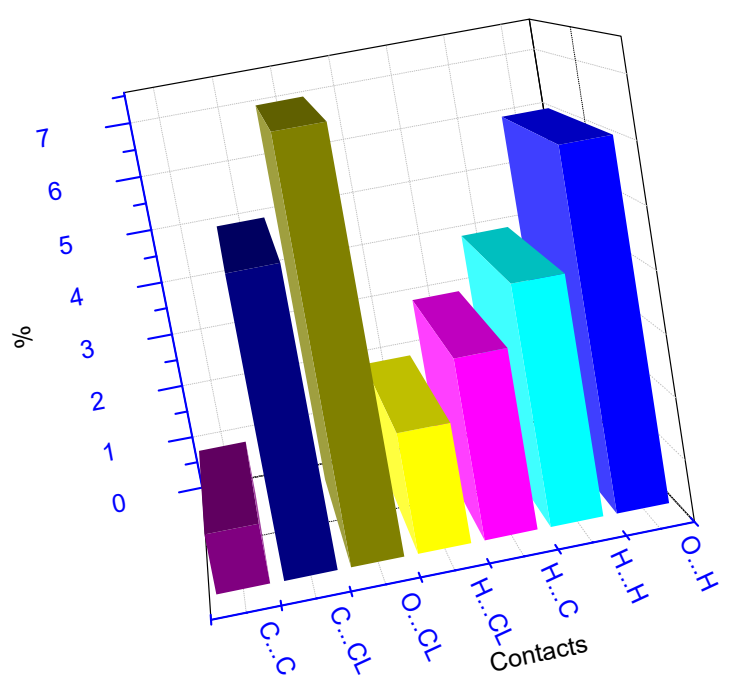

Figure 5. Percentage contributions to the Hirshfeld surface area for the various close intermolecular contacts for 2CADHP.

The Hirshfeld surface and de is the closest external contacts Figure 6, electrostatic potential mapped on Hirshfeld surface (different orientation) with \pm 0.020 a.u. Blue region corresponds to positive electrostatic potential and red region to negative electrostatic potential. Void refers to the isolated cavity and it is an important term for describing the structure of crystalline materials [28] . Voids of grown crystal at 0.002 au isosurface. The volume occupied by voids is around $8.18 \%$ of the unit cell volume.

\section{Optimized geometry}

The geometrical parameters were optimized by DFT/B3LYP, DFT/PBEPBE, HF and MP2 with 3-21G basis set are showing in Figure 7. The calculated parameters have been compared with the spatial coordinates of 2CADHP as obtained from X-ray structure analysis [29]. The theoretical bond lengths are softly longer and bond angles are slightly less than those of XRD data. The small discrepancies in bond parameters are due to the fact that theoretical calculations belong to isolated molecule and the XRD data results belong to molecules in this is hybrid, where the packing effects and intermolecular interactions play an high role in keeping molecules together. The optimized bond length of $\mathrm{C}-\mathrm{C}$ in phenyl ring fall in the range from $1.393 \AA$ to $1.405 \AA$ for PBEPBE/3-21 G, from $1.379 \AA$ to $1.381 \AA$ for $\mathrm{HF} / 3-21 \mathrm{G}$, from $1.379 \AA$ to $1.381 \AA$ for B3LYP/3-21G and from $1.393 \AA$ to $1.405 \AA$ for methods, respectively, which are reliable agreement with experimental values for $\mathrm{C}-\mathrm{C}$ bond length of phenyl ring. The amine $\mathrm{N}-\mathrm{H} . . \mathrm{O}$ has stronger in theoretical calculation due to the orientation of phosphate anion. From the theoretical values, it is observed that the most of the optimized bond lengths and bond angles are slightly larger than experimental value, because theoretical calculations carried out on molecule in gaseous phase whereas the experimental results correspond to molecules in solid crystalline states [30]. From all HF, MP2 and DFT methods with 3-21G calculations basis, the DFT//3-21G was the most accurate method used for the geometry optimization of the title molecule. 


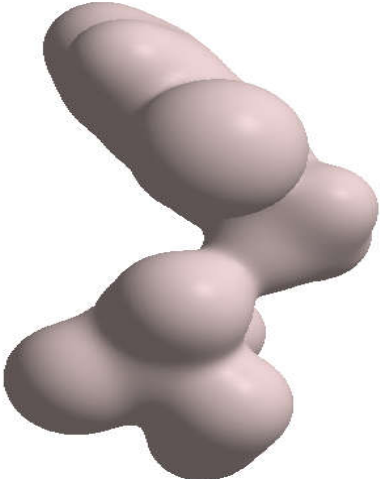

(a)

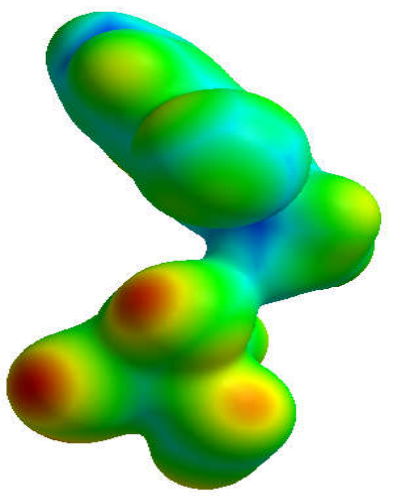

(c)

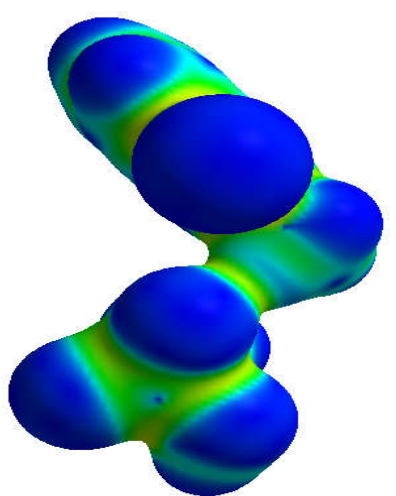

(e)

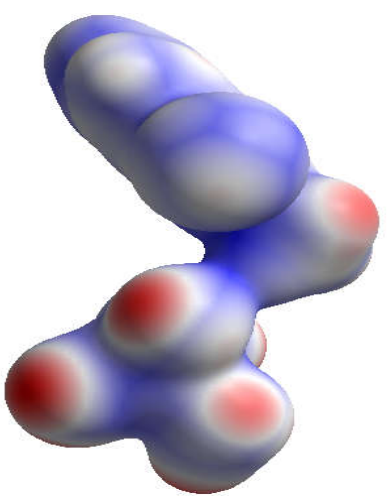

(b)

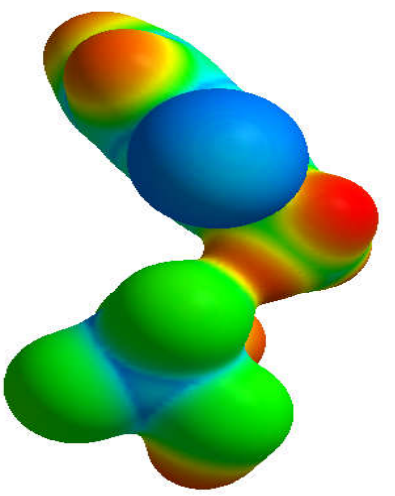

(d)

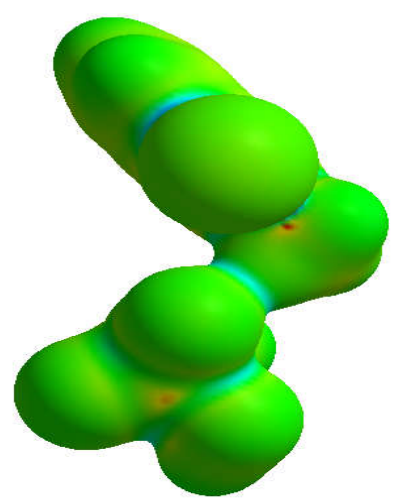

(f)

Figure 6. Electrostatic potential (PE) mapped on Hirshfeld surface of the molecule of 2CADHP: (a) none, (b) $d_{\text {norm }}$, (c) $d_{e}$, (d) $d_{i}$, (e) shape index and (f) curvedness. Bull. Chem. Soc. Ethiop. 2021, 35(3) 

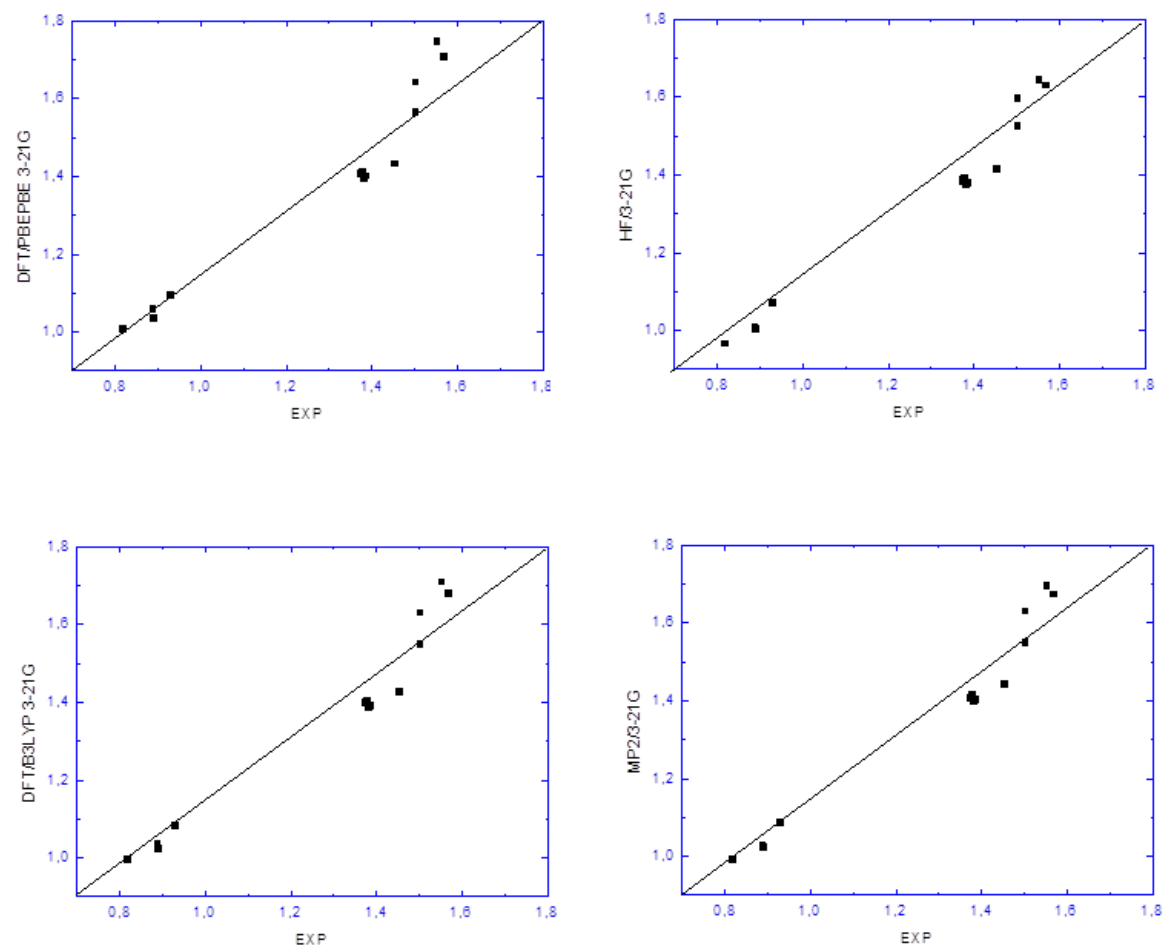

Figure 7. Graphic correlation between the experimental and the theoretical values of bond distances obtained by DFT/PBEPBE, HF, DFT/B3LYP and MP2 levels with 3-21G basis sets.

\section{Molecular electrostatic potential}

The 3D plots of the electrostatic potential (ESP), total electron density (ED) and molecular electrostatic potential (MEP) for 2-chloroanilinium dihydrogen phosphate at the PBEPBE/3-21G level are shown in Figure 8. MEP is typically visualized over mapping its values in the surface reflecting the molecules boundaries. The color scheme for the MEP and ESP surfaces is red, electron loaded, partially negative charge; blue, electron deficient, partially positive charge; light blue, slightly electron deficient region; yellow, slightly electron rich region; and green, neutral. The color code for the MEP and ESP maps is in the range between -0.0739 a.u. and $\quad-0.0217$ a.u. (deepest red) and 0.0739 a.u. and 0.0217a.u. (deepest blue) for the title molecule, respectively, where the blue color indicates the solids attractions and the red indicates the strongest repulsion. Potential increases in the order red $b$ orange $b$ yellow $b$ green $b$ blue. The molecular electrostatic potential is related to the electronic density and a very useful descriptor for determining sites for electrophilic attack and nucleophilic reactivity as well as hydrogen-bonding interactions [31, 35]. As can be seen in Figure 8, the ED plots for the hybrid of title molecule show a uniform distribution. The MEP maps of both tautomers, where as electrophilic attack is presented by negative (red) regions, nucleophilic reactivity is shown by positive (blue) regions of MEP map of both tautomers. As seen from Figure 8, the red regions are mainly localized on O4 and O3 phosphate group of the uracil ring, favorable site for electrophilic attack. On the other hand, when 
focused on positive regions of the electrostatic potential, it is observed that the amino (N1) group of the uracil ring is surrounded by blue color, indicating that these sites are probably involved in nucleophillic processes. It can be seen from the ESP. This result is expected, because ESP correlates with electronegativity and partial charges.
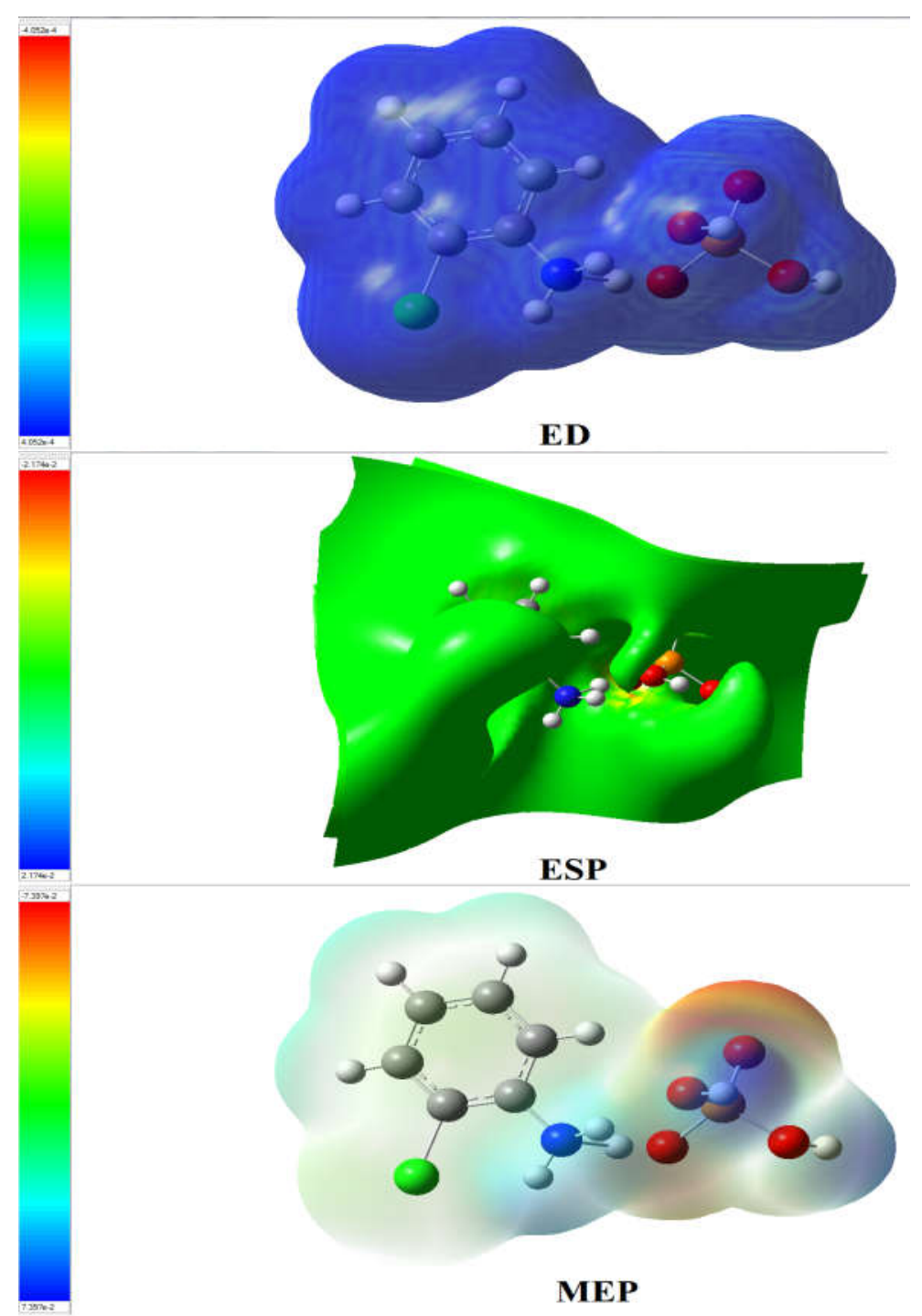

Figure 8. Total electron density (ED), electrostatic potential (ESP) and the molecular electrostatic potential (MEP) map in gas phase for 2CADHP molecule. 


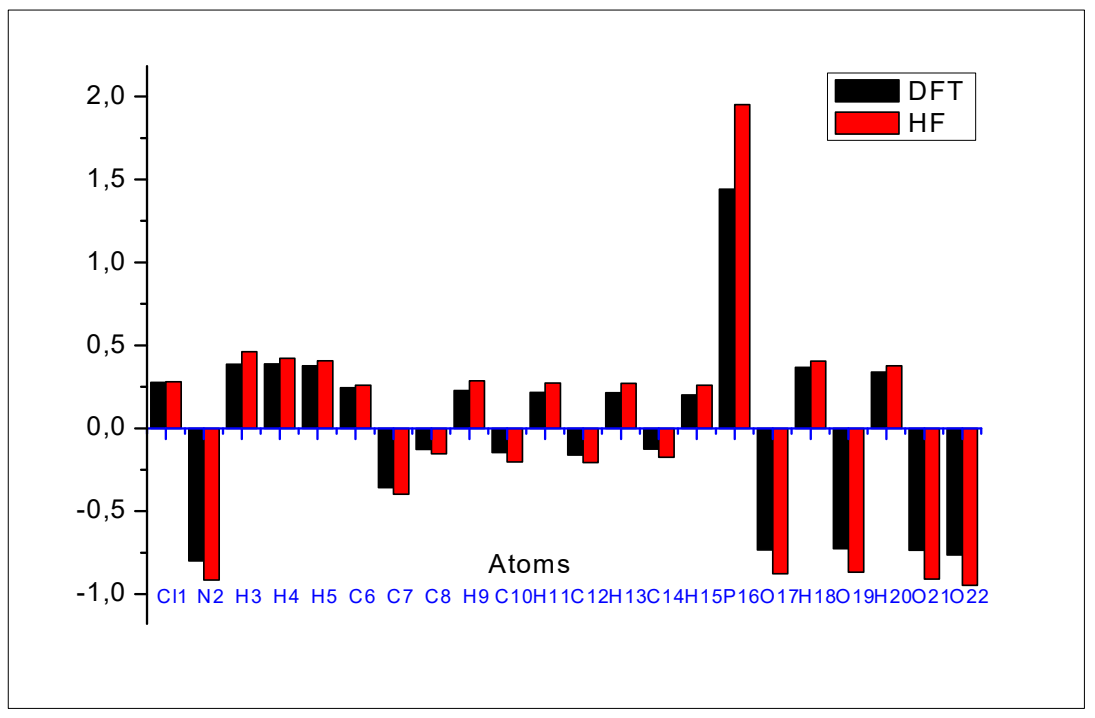

Figure 9. Mulliken population analysis chart of 2CADHP.

\section{Mulliken population analysis}

The Mulliken atomic charge distribution plays a fundamental role in the field of quantum chemical calculations. Also, an atomic charge of a molecular system gives a pictographic illustration of the charge transfer, electrophilic and nucleophilic reaction, atomic charge displacement and electrostatic potential surfaces [36]. Mulliken charges of 2-chloroanilinium dihydrogen phosphate obtained by Mulliken population analysis by HF and B3LYP methods and $3-21 \mathrm{G}$ basis set as a bar diagram in Figure 9. The result shows that substitution of dimethoxy groups on the benzene ring have redistributed the electron density unevenly over the molecule, however, better be visualized in graphical. In the present attempt, the presence of $\mathrm{N} 2$ atom creates more negative charges on carbon atoms C7 $=-0.357288 \mathrm{e}, \mathrm{C} 10=-0.146925 \mathrm{e}, \mathrm{C} 12=-0.161215 \mathrm{e}$ and $\mathrm{C} 14=-0.125168 \mathrm{e}$, when comparing with other carbon atoms in the molecule. All the hydrogen atoms have positive charges, especially $\mathrm{H} 15=0.201338 \mathrm{e}$ and $\mathrm{H} 11=0.215602 \mathrm{e}$ atom have more positivity due to the influence of $\mathrm{O}$ and $\mathrm{N} 2$ atoms, which confirms the more electro negativity of these atoms. In the five membered rings, the carbon atom C6 $=0.244911 \mathrm{e}$ exhibits more positive charges than hydrogen atom. On comparing with other atoms, the hydrogen atom H4 exhibits less positive charge of 0.387681 e, whereas N2 atom exhibits less negativity is $0.800086 \mathrm{e}$, it is also confirmed with molecular electrostatic potential surfaces.

\section{HOMO-LUMO energy gap}

The HOMO (electron donor) and LUMO (electron acceptor) are the frontier molecular orbitals that play important role in chemical reactions. The HOMO-LUMO energy gap helps to determine the chemical stability and electrical transport properties of molecules. The chemical stability of a molecule can be characterized by the gap between HOMO and LUMO [37, 38]. A small gap explains the significant degree charge transfer within the molecule from electron donor to the electron-accepter groups through conjugated path. The HOMO is delocalized mainly over the 2chloroanilinium ring, while the LUMO is delocalized mainly over the aromatic ring and Oxygen 
atom. Thus, HOMO-LUMO one electron excitation shows the charge transfer within some portion of the molecule 2CADHP. The energy gap for mentioned molecule in above has been calculated. The calculated HOMO-LUMO gap of the title molecule is $6.016 \mathrm{eV}$ by DFT/B3LYP, $4.305 \mathrm{eV}$ by DFT/PBEPBE, $5.676 \mathrm{eV}$ by HF/3-21G and $5.955 \mathrm{eV}$ by MP2/3-21G presented in Table 1 for the title compound. Usually, the total energy is relatively low but the energy gap of HOMOLUMO is small, suggesting that the stability of the compound is poor, has been used to prove the chemical reactivity and non-linear property.

Table 1. The calculated of energy HOMO, LUMO and gap of the title molecule 2CADHP.

\begin{tabular}{|c|c|c|c|}
\hline Method & Energy (HOMO) & Energy (LUMO) & Energy (gap) \\
\hline DFT//B3LYP & -0.23973 a.u. & -0.01795 a.u. & $6.016 \mathrm{eV}$ \\
\hline DFT//PBEPBE & -0.20656 a.u. & -0.04786 a.u. & $4.305 \mathrm{eV}$ \\
\hline HF//3-21G & -0.12329 a.u. & -0.33251 a.u. & $5.676 \mathrm{eV}$ \\
\hline MP2//3-21G & -0.33534 a.u. & -0.11581 a.u. & $5.955 \mathrm{eV}$ \\
\hline
\end{tabular}

\section{CONCLUSION}

With the help of crystal structure, all the Hirshfeld surfaces of 2-chloroanilinium including its fingerprint plots has been determined, further, it is the hybrid structure demonstrates that the atomic arrangement can be described by organic sheets alternated by discrete dihydrogen phosphate anions. The crystal packing cohesion is ensured by $\mathrm{N}-\mathrm{H} . . \mathrm{O}$ hydrogen bonds, van der Waals and electrostatic interactions to create a three-dimensional network. he crystal packing is stabilized by H...H type of interactions. The Hirshfeld surface and finger print analysis shows the nature of inter and intramolecular interactions and it revels the contribution of those interactions in the crystal which helps in the stabilization of the molecule. This crystallography study supports to understand the molecular structure and the intermolecular interactions of the 2CADHP compound. The theoretical study was attempted to predict the optimized geometry by the Density Functional Theory (DFT) using the B3LYP and PBEPBE functions and HF, MP2 methods with the 3-21G basis sets. Further, this is molecular correlated with the best DFT function correlation method.

\section{ACKNOWLEDGEMENTS}

The authors thank Université Ibn Tofail-Kenitra, Morocco.

\section{REFERENCES}

1. Wojtas, M.; Ga, A.; Czupinski, O.; Pietraszko, A.; Jakubas, R. 2,4,6-Trimethylpyridinium perchlorate: Polar properties and correlations with molecular structure of organic-inorganic hybrid crystal. J. Solid State Chem. 2009, 182, 3021-3030.

2. Dybtsev, D.N.; Chun, H.; Yoon, S.H.; Kim, D.; Kim, K. Microporous manganese formate: A simple metal-organic porous material with high framework stability and highly selective gas sorption properties. J. Am. Chem. Soc. 2004, 126, 32-33.

3. Smith, D.W. Chlorocuprates(II). Chem. Rev. 1976, 21, 93-158.

4. Ma, L.F.; Wang, L.Y.; Wang, Y.; Du, M.; Wang, J.G. Synthesis, structures and properties of $\mathrm{Mn}(\mathrm{II})$ coordination frameworks based on $\mathrm{R}$-isophthalate $\left(\mathrm{R}=-\mathrm{CH}_{3}\right.$ or $\left.-\mathrm{C}\left(\mathrm{CH}_{3}\right)_{3}\right)$ and various dipyridyl-type co-ligands. Cryst. Eng. Comm. 2009, 11, 109-117.

5. Almeida Paz, F.A.; Sousa, F.L.; Soares-Santos, P.C.R.; Cavaleiro, A.M.V.; Nogueira, H.I.S.; Klinowski, J.; Trindade, T. A novel supramolecular organic inorganic adduct containing a- 
Hirshfeld surface analysis and quantum chemical study of molecular structure of phosphate 637

Keggin-type $\left[\mathrm{PW}_{12} \mathrm{O}_{40}\right]^{3-}$ anions and benzo-15-crown-5 molecules. Acta Cryst. E 2004, 60, $\mathrm{m} 1-\mathrm{m} 5$.

6. Almarsson, O.; Zaworotko, M.J. Crystal engineering of the composition of pharmaceutical phases. Do pharmaceutical co-crystals represent a new path to improved medicines. Chem. Commun. 2004, 17, 1889-1896.

7. Baouab, L.; Jouini, A. Crystal structures and thermal behavior of two new organic monophosphates. J. Solid State Chem. 1988, 141, 343-351.

8. Averbuch-Pouchot, M.T.; Durif, A. Structures of ethylenediammonium monohydrogen tetraoxophosphate $(\mathrm{V})$ and ethylenediammonium monohydrogen tetraoxoarsenate $(\mathrm{V})$. Acta Cryst. C 1987, 43, 1894-1896.

9. Averbuch-Pouchot, M.T.; Durif, A.; Guitel, J.C. Structures of glycine monophosphate and glycine cyclo-triphosphate. Acta Cryst. C 1988, 44, 99-102.

10. Averbuch-Pouchot, M.T.; Durif, A.; Guitel, J.C. Structure of ethylenediammonium dihydrogentetraoxophosphate pentahydrogen bis[tetraoxophosphate(V)]. Acta Cryst. C 1989, 45, 421- 423.

11. Patel, K.D.; Patel, U.H. Quantitative analysis of weak interactions by lattice energy calculation, Hirshfeld surface and DFT studies of sulfamonomethoxine. J. Mol. Struct. 2017, $1128,127-134$.

12. Agilandeswari, R.; Aditya Prasad, A.; Sivaraman, S.; Kalainathan, S.; Meenakshisundaram, S.P. Hyperpolarizability, Hirshfeld, and density functional theory computations of a nonlinear optical picrate. Mol. Cryst. Liq. Cryst. 2016, 625, 238-252.

13. Frisch, M.J.; Trucks, G.W.; Schlegel, H.B.; Scuseria, G.E.; Robb, M.A.; Cheeseman, J.R.; Montgomery Jr., J.A.; Vreven, T.; Kudin, K.N.; Burant, J.C.; Millam, J.M.; Iyengar, S.S.; Tomasi, J.; Barone, V.; Mennucci, B.; Cossi, M.; Scalmani, G.; Rega, N.; Petersson, G.A.; Nakatsuji, H.; Hada, M.; Ehara, M.; Toyota, K.; Fukuda, R.; Hasegawa, J.; Ishida, M.; Nakajima, T.; Honda, Y.; Kitao, O.; Nakai, H.; Klene, M.; Li, X.; Knox, J.E.; Ratchian, H.P.; Cross, J.B.; Adamo, C.; Jaramillo, J.; Gomperts, R.; Stratmann, R.E.; Yazyev, O.; Austin, A.J.; Cammi, R.; Pomelli, C.; Ochterski, J.W.; Ayala, P.Y.; Morokuma, K.; Voth, G.A.; Salvador, P.; Dannenberg, J.J.; Zakrzewski, V.G.; Dapprich, S.; Daniels, A.D.; Strain, M.C.; Farkas, O.; Malick, D.K.; Rabuck, A.D.; Raghavachari, K.; Foresman, J.B.; Ortiz, J.V.; Cui, Q.; Baboul, A.G.; Clifford, S.; Cioslowski, J.; Stefanov, B.B.; Liu, G.; Liashenko, A.; Piskorz, P.; Komaromi, I.; Martin, R.L.; Fox, D.J.; Keith, T.; Al-Laham, M.A.; Peng, C.Y.; Nanayakkara, A.; Challacombe, M.; Gill, P.M.W.; Johnson, B.; Chen, W.; Wong, M.W.; Gonzalez, C.; Pople, J.A. Gaussian 03, Revision A.1, Gaussian Inc.: Pittsburgh, PA; 2003.

14. Rahut, G.; Pulay, R. Transferable scaling factors for density functional derived vibrational force fields. J. Phys. Chem. 1995, 99, 3093-3100.

15. Pulay, R.; Fogarasi, G.; Pongor, G.; Boggs, J.E.; Vargha, A. Combination of theoretical ab initio and experimental information to obtain reliable harmonic force constants. Scaled quantum mechanical (QM) force fields for glyoxal, acrolein, butadiene, formaldehyde, and ethylene. J. Am. Chem. Soc. 1983, 105, 7037-7047.

16. Becke, A.D. Density-functional exchange-energy approximation with correct asymptotic behavior. Phys. Rev. A 1988, 38, 3098-3100.

17. Fogarasi, G.; Pulay, P.; Durig (Ed.), J.R. Vibrational Spectra and Structure, Elsevier: Amsterdam; 1985, 14, 125-219.

18. Raja, G.; Saravanan, K.; Sivakumar, S. Ab initio molecular orbital and density functional theoretical studies on1-naphtol. Int. J. Appl. Phys. Math. 2011, 1, 118-123.

19. Hudson, P.; Robertson, J.H. The crystal and molecular structure of $\beta$-thiophenic acid. Acta Cryst. 1964, 17, 1497-1505.

20. Visser, G.J.; Heeres, G.J.; Wolters, J.; Vos, A. Disorder in crystals of the dithienyls and $\beta$ thiophenic acid. Acta Cryst. B 1968, 24, 467-473.

21. Shridhar, D.R.; Sastry, C.V.R.; Chaturvedy, S.C.; Grumurthy, R.; Sing, P.P.; Rao, C.S.; 
Junnarkar, A.Y. Synthesis and pharmacology of some new oxime ethers derived from 2acetyl-5-arylthiophenes. Indian J. Chem. 1984, 23, 692-694.

22. Macrae, C. F.; Edgington, P.R.; McCabe, P.; Pidcock, E.; Shields, G.P.; Taylor, R.; Towler, M.; van de Streek, J. Visualization and analysis of crystal structures. J. Appl. Cryst. 2006, 39, 453-457.

23. Wolff, S.K., Grimwood, D.J., McKinnon, J.J., Turner, M.J., Jayatilaka, D., Spackman, M. A. Crystal Explorer, University of Western, Australia: Australia; 2012.

24. Yaman, M.; Almarhoon, Z.M.; Cakmak, S.; Kutuk, H.; Meral, G.; Dege, N. Synthesis, crystal structure, spectroscopic features and Hirshfeld surfaces of 2-methyl-3-[(2methylphenyl)carbamoyl]phenyl acetate. Acta Cryst. E 2018, 74, 41-44.

25. McKinnon, J.J.; Jayatilaka, D.; Spackman, M.A. Towards quantitative analysis of intermolecular interactions with Hirshfeld surfaces. Chem. Commun. 2007, 37, 3814-3816.

26. Balamurugan, P.; Jagan, R.; Sivakumar, K. Dihydrogen phosphate mediated supramolecular frameworks in 2- and 4-chloroanilinium dihydrogen phosphate salts. Acta Cryst. 2010, C66, o109-o113.

27. Spackman, M.A.; Jayatilaka, D. Hirshfeld surface analysis. Cryst. Eng. Comm. 2009, 11, 1932.

28. Meindl, K.; Henn, J. Foundations of residual-density analysis. Acta Cryst. 2008, 64, 404-418.

29. Li, Z.J.; Chen, X.M.; Ren, Z.X.; Li, Y.; Chen, X.A.; Huang, Z.T. Crystal and molecular structure of hexahydro-2-(nitro-benzoylmethylene)pyrimidine. Chin. J. Struct. Chem. 1997, 16, 311-315.

30. Kamoun, S.; Jouini, A. Etude calorimétrique et structure cristalline du putresciniummonohydrogénomonophosphatedihydrate $\mathrm{NH}_{3}\left(\mathrm{CH}_{2}\right)_{4} \mathrm{NH}_{3} \mathrm{HPO}_{4} 2 \mathrm{H}_{2} \mathrm{O}$. J. Solid State Chem. 1990, 89, 67-74.

31. Vijayakumar, T.; Joe, H.; Nair, C.P.R.; Jayakumar, V.S. Efficient pi-electrons delocalization in prospective push-pull non-linear optical chromophore 4-[N,N-dimethylamino]-4'-nitro stilbene. Chem. Phys. 2008, 343, 83-99.

32. Atalay, Y.; Başoğlu, D.A.A. Linear and non-linear optical properties of some donor-acceptor oxadiazoles by ab initio Hartree-Fock calculations. Struct. Chem. 2008, 19, 239-246.

33. Xia, Y.; Yao, H.; Cui, M.; Ma, Y.; Kong, Z.; Wu, B.; Qi, Z.; Sun, Y. Theoretical and experimental investigations on mono-substituted and multi-substituted functional polyhedral oligomericsilsesquioxanes. RSC Adv. 2015, 5, 80339-80345.

34. Politzer, P.; Murray, J.S. Molecular electrostatic potentials and chemical reactivity. Rev. Comput. Chem. 1991, 273-312.

35. Scrocco, E.; Tomasi, J. Electronic molecular structure, reactivity and intermolecular forces: An euristic interpretation by means of electrostatic molecular potentials. Adv. Quantum Chem. 1978, 11, 115-193.

36. Mulliken, R.S. Electronic population analysis on LCAOMO molecular wave functions. $J$. Chem. Phys. 1955, 23, 1833-1840.

37. Gunasekaran, S.; Balaji, R.A.; Kumaresan, S.; Anand, G.; Srinivasan, S. Experimental and theoretical investigations of spectroscopic properties of N-acetyl-5-methoxytryptamine. Can. J. Anal. Sci. Spectrosc. 2008, 53,149-162.

38. Arivazhagan, M.; Krishnakumar, V.; John Xavier, R.; Illango, G.; Balachandran, V. FTIR, FT-Raman, scaled quantum chemical studies of the structure and vibrational spectra of 1,5dinitronaphthalene. Spectrochim. Acta Part A 2009, 72, 941-946. 